American Journal of Pharmaceutical Education 2017; 81 (3) Article 47.

\title{
RESEARCH
}

\section{Performance and Perceptions of Student Teams Created and Stratified Based on Academic Abilities}

\author{
Lana Dvorkin Camiel, PharmD, Maria Kostka-Rokosz, PharmD, Gary Tataronis, MS, \\ Jennifer Goldman, PharmD \\ Massachusetts College of Pharmacy and Health Sciences, Boston, Massachusetts
}

Submitted October 23, 2015; accepted February 4, 2016; published April 2017.

Objective. To compare student performance, elements of peer evaluation and satisfaction of teams created according to students' course entrance grade point average (GPA).

Methods. Two course sections were divided into teams of four to five students utilizing Comprehensive Assessment of Team Member Effectiveness (CATME) software.

Results. Of 336 students enrolled, 324 consented to participation. Weekly team quiz averages were 99.1\% (higher GPA), 97.2\% (lower GPA), 97.7\% (mixed GPA). Weekly individual quiz averages were 87.2\% (higher GPA), 83.3\% (lower GPA), 85.2\% (mixed GPA). Students with same GPA performed similarly individually independent of team assignment. Satisfaction ranged from 4.52 (higher GPA), 4.73 (lower GPA), 4.53 (mixed GPA).

Conclusion. Academically stronger students in mixed GPA teams appeared to be at a slight disadvantage compared to similar students in higher GPA teams. There was no difference in team performance for academically weaker students in lower GPA versus mixed GPA teams. Team satisfaction was higher in lower GPA teams.

Keywords: teamwork, team allocation, performance, satisfaction, large classroom

\section{INTRODUCTION}

Teamwork is a crucial component of learning because it promotes student active engagement, which leads to long-term retention of the content. ${ }^{1}$ Teamwork can be used in a variety of educational methods including teambased learning, problem-based learning, flipped classroom, blended learning and more. ${ }^{2,3}$ The importance of effective teamwork is gaining prominence in the research arena. Some of the elements of teamwork that have been explored include collective intelligence, ${ }^{4}$ gender roles, ${ }^{4}$ team construction (ie, ability grouping, ${ }^{5,6}$ personality and learning style inventories ${ }^{7}$ ), and individual contributions. ${ }^{8}$

Research in elementary education suggests that students should be placed in heterogeneous groups for the majority of instruction, but should be regrouped according to their abilities for skill development activities such as reading and mathematics. Instructors need to re-evaluate students' achievement level frequently and change groups accordingly. ${ }^{5}$ Cheng and colleagues evaluated the performance of close to 2,000 students who participated in a yearlong project-based learning program in secondary

Corresponding Author: Lana Dvorkin Camiel, MCPHS University, 179 Longwood Ave., Boston, MA 02115. Tel: 617-732-2915. Fax: 617-732-2236. E-mail: Lana.dvorkin@ mcphs.edu schools. ${ }^{6}$ They found that high achievers performed better on their own than with a group, when group processes were of low quality. ${ }^{6}$ However, both high and low achievers performed better in a group, when group processes were of high quality. ${ }^{6}$ Group processes of high quality include positive interdependence, individual accountability, equal participation and social skills. ${ }^{6}$

Pharmacy educators advocate putting students into heterogeneous teams to ensure a diverse mix of backgrounds, experiences, and learning styles that will prepare students for pharmacy practice. ${ }^{9}$ Often, teams are created randomly to save time. Many instructors invite students to participate in the exercises/questionnaires where they can explore their own personalities, strengths and weaknesses, learning styles and preferences. ${ }^{7,10,11}$ The process of self-discovery can be time-consuming but valuable for students. Even though the process of assigning students to specific teams is often laborious, course coordinators are often interested in a more precise team formation. Students can be assigned to teams based on their scholastic performance, work experience, social background, leadership preference, learning style and more. Some learning style inventories include the Strengths Finder; the MyersBriggs Type Indicator; Keirsey Temperament Sorter; Pharmacists' Inventory of Learning Styles; Kolb Learning 


\section{American Journal of Pharmaceutical Education 2017; 81 (3) Article 47.}

Style Inventory; Visual, Aural, Read/Write, Kinesthetic Questionnaire VARK. ${ }^{7,10,11}$

Another challenge with team learning is assessing both team and individual member contributions. To remedy this, faculty rely on peer evaluations. However, because it is common for students to give all their teammates the same positive score to avoid confrontation or negative feeling, it is hard to gauge the accuracy and reliability of peer evaluations. We noticed that students grade their peers harshly only when they observe workload inequalities. Peer evaluations maybe more meaningful when a "budgeted" approach is used. In this method, a total score is divided among team members based on merit. ${ }^{12}$

The Comprehensive Assessment of Team Member Effectiveness (CATME) Smarter Teamwork (West Lafayette, IN) is software that includes web-based tools developed by researchers at Purdue University. ${ }^{13}$ There are a number of publications in various disciplines that describe the use of these tools. ${ }^{14-19}$ The main goal of CATME Smarter Teamwork is to assist faculty in team management. After requesting an account, faculty are granted access to the system and all the tools, including CATME Faculty Team-Management Guide, CATME Students Teamwork Training, CATME Team-Maker, CATME Peer Evaluation and CATME Rater Calibration. The CATME Team-Maker allows for collection of information about students and setting specific criteria that are later used to create teams. In Rater Calibration, students are invited to use mock team members to learn how to best evaluate their contributions. In Peer Evaluation, students self- and peer evaluate each team member on five criteria of teamwork.

In this study, we examined if purposeful team formation and evaluation through the CATME Smarter Teamwork would be beneficial to team member satisfaction and overall performance in a large pharmacy course. The objective of this study is to compare student performance, elements of peer evaluation and student satisfaction with their team created according to students' course entrance grade point average (GPA).

\section{METHODS}

Based on positive reviews from pharmacy academicians working with large classe ${ }^{20-23}$ and to achieve consistency of the content delivery, our team of faculty incorporated flipped team-based learning in a required self-care course consisting of over 300 students divided into two sections. The three-credit course met once a week for 14 weeks. In this design, students reviewed prerecorded content prior to coming to class and in-class sessions were used for case-based application of the material after completion of individual and team Readiness
Assurance Tests (iRATs/tRATs) consisting of 5-10 multiple choice questions. ${ }^{24,25}$ During the first year of the course's re-design to flipped team-based learning format, the students were randomly assigned to teams of four to five individuals to promote participation and accountability. ${ }^{7,26}$ Twice during the semester, students were asked to use Google Forms to submit peer-evaluations of team members. Due to the large class size, both team formation and peer evaluations grading were heavily time consuming for us. We sought out tools to help address these concerns.

After attending a seminar about team formation/peer evaluation using the CATME Smarter Teamwork system ${ }^{13}$ and exploring current literature on team formation in team-based learning, ${ }^{27-29}$ we made the decision to utilize it in the fall of second year of the course re-design. We used CATME.org to create two student cohorts (section A and section B) based on Registrar student course section allocation. A set of questions (some native to the CATME system and others developed by course coordinators) was used to create a Team Formation Survey. The Team Formation Survey included questions about students' gender, English level proficiency, introvert/extrovert personality types, leadership role preference, pharmacy work experience, over-the-counter drugs/self-care work experience, and group work preference. We created the Team Formation Survey and Student Feedback Survey instruments and revised them over a several meetings with input from faculty who were teaching the course.

Rosters from each section including names, identification numbers, email addresses and cumulative GPA ranges $(1=2.00-2.69 ; 2=2.70-2.99 ; 3=3.00-3.49$; $4=3.50-4.00)$ were uploaded into the software. Once uploaded, students received an invitation email to signup for CATME account and complete the Team Formation Survey. Since the first Monday of the semester was a holiday, students were asked to complete the survey by day 3 of that week. On day 4 using CATME software, we created teams based on student responses, allowing them to meet the following Monday in their permanent teams.

The software allows faculty to assign weight to selected variables from the Team Formation Survey. In this class, the highest weight was given to the GPA ranges, followed by responses of English level proficiency and leadership role preference. The last two criteria were evenly distributed between teams, however section A consisted of homogeneous teams (higher GPA between 3.00-4.00/lower GPA 2.00-2.99) and section B of heterogeneous teams (mixed GPA). Students did not know what type of team they were placed in.

During the course, students were required to evaluate team members twice based on the following five 


\section{American Journal of Pharmaceutical Education 2017; 81 (3) Article 47.}

research-based CATME criteria $^{14}$ : contributing to the team's work, interacting with teammates, keeping the team on track, expecting quality, and having related knowledge, skills and abilities. An in-class tutorial was presented after which students were invited to participate in a mandatory CATME Rater Calibration activity to prepare them for meaningful team evaluation and for better familiarity with CATME. The software presented evaluation scores and comments of the entire team to each student anonymously.

Final course teamwork grades $(20 \%$ of the final grade) were based on two separate elements: average academic performance on tRATs and each individual student's contribution to the team effort (determined by peer evaluation grade). For example, if students gave their team member $90 \%$ in peer evaluation score, the student's average tRAT performance grade would be multiplied by $90 \%$. If a student participates only partially in teamwork, this more accurately reflected their contribution to the teamwork.

In addition, at course completion, students evaluated the software and elements of teamwork in a voluntary confidential Student Feedback Survey. The Student Feedback Survey instrument consisted of questions about ease of CATME navigation, utility of CATME Rater Calibration activity, applicability of CATME peer evaluation criteria, degree of fairness of peer evaluations, preference for random versus response-based team formation strategy, and suitability of team members in terms of personal and professional characteristics. The 19-question survey (available upon request) was delivered via the Qualtrics online survey platform (Qualtrics Labs, Inc, Provo, UT). ${ }^{30}$ A Likert scale was utilized for the majority of questions. Participation in the survey was voluntary and students received bonus points for completing the survey. Students enrolled in the course were emailed an informed consent form and a link to the survey. Clicking on the link implied students' consent.

Finally, data from the Team Formation Survey, student peer evaluations, Student Feedback Survey, student performance during tRATs, iRATs and exams, as well as GPA ranges prior to course entrance were used for the overall analysis for students that consented to participating in this project. The Qualtrics online survey platform tabulated the responses and provided descriptive statistics. Chi-square in combination with Marascuilo's post-hoc analyses were used to assess for significant correlations between student responses to select Team Formation and Student Feedback Survey questions versus higher/lower/mixed GPA Team. Analysis of Variance (ANOVA) with Tukey-Kramer multiple comparisons were used to determine whether significant differences existed in mean iRAT, tRAT, exams, and CATME peer-evaluation criteria scores between higher/lower/ mixed GPA teams. All analyses were performed using either NCSS $2007^{31}$ or StatsToDo. ${ }^{32}$ Results were considered statistically significant if the observed level of significance was $p<.05$.

The university's Institutional Review Board approved the research and the survey instruments.

\section{RESULTS}

Three hundred thirty-six students were enrolled in the course, and $324(96 \%)$ consented to participate in the project. There were 20 higher GPA teams ( 81 students), 23 lower GPA teams ( 89 students), and 39 mixed GPA teams (154 students). The baseline characteristics of the participants are described in Table 1.

During the course, students evaluated their team members on teamwork based on five CATME criteria. Averages of their evaluation grades and their overall team satisfaction are included in Table 2. Scores on these evaluation criteria - contribution to team, keeping team on track, and having knowledge, skills and attitudes - were statistically significantly greater in higher GPA teams than in either lower GPA or mixed GPA teams. On average, all students enrolled in the course gave each other lower scores on the contribution to team and keeping team on track criteria.

Averages of weekly team quizzes (tRATs) were 99.0\% (higher GPA), 97\% (lower GPA), 98\% (mixed GPA). These finding were statistically significant for higher and lower, as well as higher and mixed teams; but not for lower and mixed $(p<.05, p<.05, p>.05$ respectively). Averages of weekly individual quizzes (iRATs) were $87 \%$ (higher GPA), 83\% (lower GPA), 85\% (mixed GPA) $(p<.05$ for all GPA groups). Table 3 breaks down student iRAT scores according to their GPA range and team assignment. Averages of three exams were $87 \%$ (higher GPA), 83\% (lower GPA), 85\% (mixed GPA) ( $p<.05$ for all GPA teams). Table 4 separates exam scores according to student GPA ranges and team assignment.

In the Student Feedback Survey, the students strongly agreed/agreed that CATME software was easy to navigate $(85 \%)$, calibration activity was useful in understanding the setup of peer evaluation form (51\%), calibration activity was useful in preparing students how to evaluate team members (45\%), peer evaluation questions were reasonably applicable to the activities performed in the course $(64 \%)$, and team members evaluated them fairly $(86 \%)$. Data on the students' perceptions of suitability of team members in terms of personal and professional characteristics from higher/lower/mixed GPA teams are described in Table 5. 


\section{American Journal of Pharmaceutical Education 2017; 81 (3) Article 47.}

Table 1. Students' Baseline Characteristics

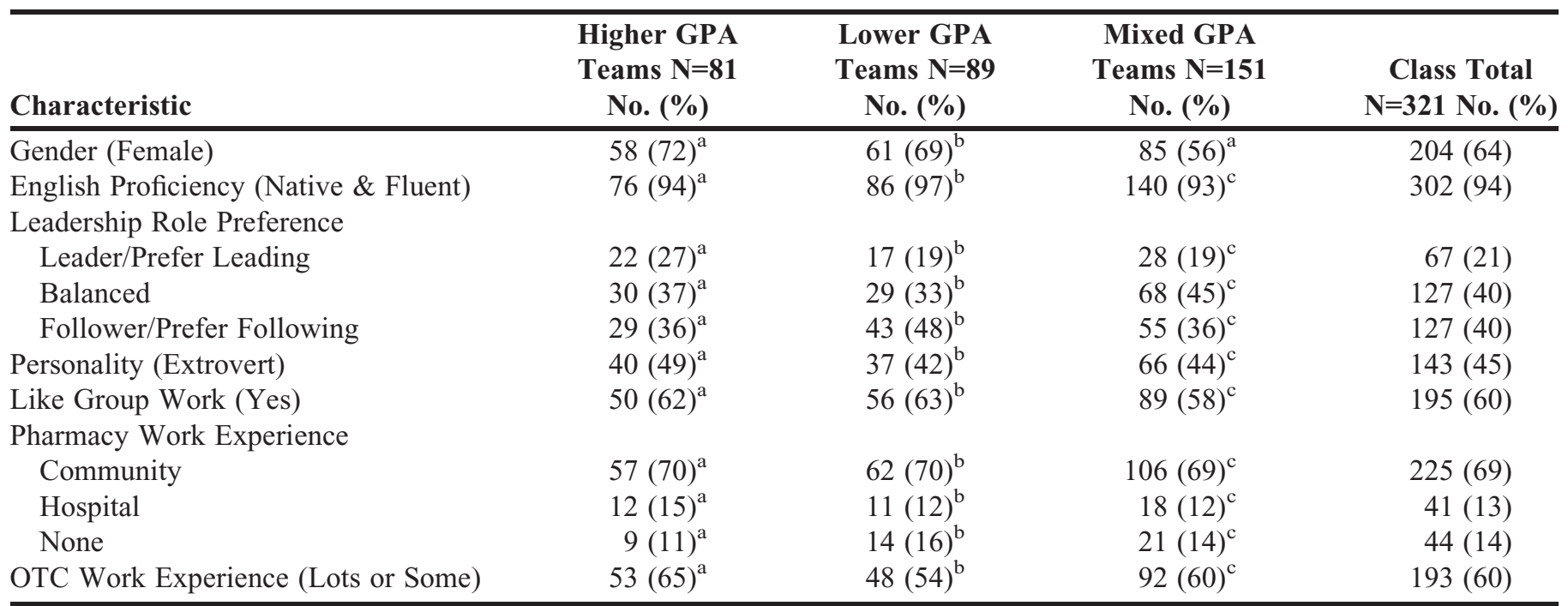

$\overline{\mathrm{a}, \mathrm{b}, \mathrm{c}}$ Within each row, values sharing common superscripts are significantly different from each other $(p<.05)$

Table 2. Peer Evaluation Grades and Satisfaction (Mean (SD); Maximum=5.00)

\begin{tabular}{|c|c|c|c|c|}
\hline Evaluation Criteria & $\begin{array}{l}\text { Higher GPA } \\
\text { Teams N=81 }\end{array}$ & $\begin{array}{c}\text { Lower GPA } \\
\text { Teams N=89 }\end{array}$ & $\begin{array}{c}\text { Mixed GPA } \\
\text { Teams } \mathrm{N}=154\end{array}$ & $\begin{array}{c}\text { Class Total } \\
\qquad=324\end{array}$ \\
\hline Contribution to Team & $4.45(0.36)^{\mathrm{a}, \mathrm{b}}$ & $4.18(0.42)^{\mathrm{a}}$ & $4.28(0.38)^{\mathrm{b}}$ & $4.29(0.40)$ \\
\hline Keeping Team on Track & $4.38(0.36)^{\mathrm{a}, \mathrm{b}}$ & $4.17(0.34)^{\mathrm{a}}$ & $4.26(0.36)^{\mathrm{b}}$ & $4.26(0.36)$ \\
\hline Expecting Quality & $4.46(0.33)^{\mathrm{a}}$ & $4.37(0.30)^{\mathrm{b}}$ & $4.35(0.34)^{\mathrm{a}}$ & $4.38(0.33)$ \\
\hline Having Knowledge, Skills, Attitudes & $4.53(0.34)^{\mathrm{a}, \mathrm{b}}$ & $4.33(0.33)^{\mathrm{a}}$ & $4.39(0.33)^{\mathrm{b}}$ & $4.41(0.34)$ \\
\hline Pleased with the way I and teammates work together & $4.56(0.58)^{\mathrm{a}}$ & $4.68(0.49)^{\mathrm{b}}$ & $4.53(0.66)^{\mathrm{c}}$ & $4.58(0.60)$ \\
\hline Very satisfied in working with this team & $4.51(0.59)^{\mathrm{a}}$ & $4.69(0.50)^{\mathrm{a}, \mathrm{b}}$ & $4.47(0.70)^{\mathrm{b}}$ & $4.54(0.63)$ \\
\hline
\end{tabular}

Within each row, values sharing common superscripts are significantly different from each other $(p<.05)$

Peer evaluation grades range from 1 (lowest) to 5 (highest)

Table 3. GPA Range vs. iRAT Scores. Mean (SD)

\begin{tabular}{lcccc}
\hline GPA Range & High GPA Teams N=81 & Low GPA Teams N=89 & Mixed GPA Teams N=154 & $\boldsymbol{p}$ \\
\hline 2.00 to 2.69 & NA & $82.9(6.0)$ & $82.7(7.2)$ & 0.87 \\
2.70 to 2.99 & NA & $83.9(5.6)$ & $84.9(6.1)$ & 0.54 \\
3.00 to 3.49 & $87.1(5.7)$ & NA & $85.8(6.0)$ & 0.29 \\
3.50 to 4.00 & $88.3(4.5)$ & NA & $89.5(5.1)$ & 0.37 \\
\hline
\end{tabular}

$\mathrm{NA}=$ None Available

\section{DISCUSSION}

In our first year of implementing team-based learning, students were randomly assigned to teams. We were concerned that putting more than 300 students in teams based on specific criteria would be too time consuming. In the second year of course redesign, CATME allowed us to easily collect information about students (such as leadership style, language, work experience). Student responses from Team Formation Survey as well as GPA ranges were utilized to create meaningful/complementary teams in a few hours rather than weeks without CATME.

The teams we created were comparable in terms of their English language proficiency and personality (introvert/extrovert). Statistically teams were similar in terms of work experience, OTC work experience and their preference for team work. Even though there was no statistical difference in leadership role preference, numerically, there were more students that preferred leading in 


\section{American Journal of Pharmaceutical Education 2017; 81 (3) Article 47.}

Table 4. GPA Range versus Exam Scores. Mean (SD)

\begin{tabular}{lcccc}
\hline GPA Range & High GPA Teams N=81 & Low GPA Teams N=89 & Mixed GPA Teams N=154 & $\boldsymbol{p}$ \\
\hline 2.00 to 2.69 & NA & $82.6(4.9)$ & $81.5(5.7)$ & 0.26 \\
2.70 to 2.99 & NA & $84.3(4.2)$ & $85.7(4.9)$ & 0.22 \\
3.00 to 3.49 & $86.9(3.9)$ & NA & $86.7(3.9)$ & 0.85 \\
3.50 to 4.00 & $89.1(3.3)$ & NA & $90.2(3.2)$ & 0.23 \\
\hline
\end{tabular}

$\mathrm{NA}=$ None Available

Table 5. Suitability of Team Members in Terms of Personal and Professional Characteristics

\begin{tabular}{|c|c|c|c|c|}
\hline Strongly Agree/Agree Responses Only from a Likert Scale & $\begin{array}{c}\text { Higher GPA } \\
\text { Teams } N=81 \\
\text { No. }(\%)\end{array}$ & $\begin{array}{c}\text { Lower GPA } \\
\text { Teams N=89 } \\
\text { No. }(\%)\end{array}$ & $\begin{array}{c}\text { Mixed GPA } \\
\text { Teams N=154 } \\
\text { No. }(\%)\end{array}$ & $\begin{array}{c}\text { Class Total } \\
\text { N=324 } \\
\text { No. }(\%)\end{array}$ \\
\hline$\overline{\text { CATME was superior to random allocation }}$ & $64(79)^{\mathrm{a}}$ & $58(65)^{b}$ & $98(64)^{\mathrm{a}}$ & $220(68)$ \\
\hline My team members were similar to me in terms of personality & $56(69)^{\mathrm{a}}$ & $66(74)^{b}$ & $85(55)^{\mathrm{b}}$ & 207 (64) \\
\hline My team members were similar to me in terms of intellectual ability & $72(89)^{\mathrm{a}}$ & $75(84)^{b}$ & $115(75)^{\mathrm{a}}$ & $262(81)$ \\
\hline My team members were similar to me in terms of work ethic & $72(89)^{\mathrm{a}}$ & $70(79)^{\mathrm{b}}$ & $109(71)^{\mathrm{a}}$ & $251(77)$ \\
\hline My team members were similar to me in terms of work style & $63(78)^{\mathrm{a}}$ & $65(73)^{b}$ & $94(61)^{\mathrm{a}}$ & $222(69)$ \\
\hline My team members were able to bring out my strengths & $58(72)^{\mathrm{a}}$ & $67(75)^{\mathrm{b}}$ & $84(55)^{\mathrm{a}, \mathrm{b}}$ & $209(65)$ \\
\hline My team members were able to decrease my weaknesses & $54(67)^{\mathrm{a}}$ & $60(67)^{b}$ & $80(52)^{\mathrm{a}, \mathrm{b}}$ & $194(60)$ \\
\hline My team members were able to complement each other & $73(90)^{\mathrm{a}}$ & $80(90)^{b}$ & $121(79)^{\mathrm{a}, \mathrm{b}}$ & $274(85)$ \\
\hline My team members were able to resolve conflicts & $68(84)^{a}$ & $78(88)^{\mathrm{b}}$ & $118(77)^{\mathrm{c}}$ & $264(81)$ \\
\hline I liked that we had the same team for the entire semester & $73(90)^{\mathrm{a}}$ & $83(93)^{b}$ & $128(83)^{b}$ & $284(88)$ \\
\hline I got to know my team members well & $74(91)^{\mathrm{a}}$ & $77(87)^{b}$ & $112(73)^{\mathrm{a}, \mathrm{b}}$ & $263(81)$ \\
\hline
\end{tabular}

Within each row, values sharing common superscripts are significantly different from each other $(p<.05)$

higher GPA teams, more students that preferred a balanced role in mixed GPA teams, and more students that preferred following in lower GPA teams. These findings were consistent with our expectations and the literature. ${ }^{33}$ Research suggests that teams with more females perform better on a social sensitivity scale, therefore there is a possible expectation that teams with more females would perform better overall. ${ }^{4}$ Based on our results, there were more females than males in higher and lower GPA than in mixed GPA teams. Since the large number of our students in higher and lower GPA teams were female, this hindered evaluation of whether gender was a major contributing factor in team performance. Even though we expected that mixed GPA teams would do better than lower GPA teams based on their overall performance prior to start of the course, they performed similarly to lower GPA teams which had more females.

As we evaluated CATME criteria, we felt that the results from students' peer evaluations may be due to the fact that they prepared for classes and interacted well; however, they still struggled keeping each other on task and contributing valuable information that helped their team to succeed.

Based on all satisfaction questions, students in lower GPA teams were overall more satisfied with their team members than their counterparts in higher or mixed GPA teams. We suspect that lower GPA teams enjoyed working together because of less challenging environment, while higher GPA teams were not held back by academically weaker students. The individual performance (iRATs and exams) differed between the teams, with higher GPA teams earning half a letter grade more than lower GPA teams. Similar to previous research on team task performance, ${ }^{4}$ however, all the teams performed well on tRATs. Scores were very close to each other despite statistically significant difference between higher GPA and other teams. The literature recommends putting students in mixed teams. ${ }^{5}$ We were surprised to discover that mixed GPA teams performed similarly to lower GPA teams in team assessments; however, they were less satisfied than the lower GPA teams. This made the experience in mixed GPA teams less preferable from both perspectives.

We initially theorized that the effect of teamwork will only influence team performance (tRATs); however, recent research shows that students placed in weaker teams perform lower even on individual assessments (iRATs). ${ }^{34}$ This suggests that team dynamics has a bigger effect on individuals. We wonder if higher performing teams have richer discussions during their time together and as a result they are better prepared for future assessments. Some faculty might argue that placing students in 


\section{American Journal of Pharmaceutical Education 2017; 81 (3) Article 47.}

weaker teams sets them up for lower performance from the start.

However, we did not observe this phenomenon in our study because students within the same GPA range performed similarly on iRATs and exams independently of their team assignment. Also, higher performing students in mixed teams ended up at a slight disadvantage to their counterparts in higher GPA teams due to a statistically but not academically significant difference on tRAT grades $97 \%$ versus $99 \%$.

As expected, students in higher and lower GPA teams reported they were more similar to each other in terms of personality, intellectual ability, work ethic, work style, their ability to bring out strengths, decrease weaknesses, complement each other, and resolve conflicts than students in mixed GPA teams. Additionally, students in higher and lower GPA teams reported that they got to know each other better and liked having the same team for the duration of the entire semester compared to those in mixed GPA teams. We question if students in lower GPA teams might be less competitive with each other, and less likely to deliver criticism to team members than students in other teams, and as a result enjoyed the team experience more. Students in higher GPA teams preferred CATME team member allocation more than students in lower and mixed GPA teams. We suspect that higher GPA teams appreciated this breakdown because typical heterogeneous environments present them with more challenges and possibly frustrations related to differences in team member abilities/personalities. Having students work in mixed teams, however, more closely resembles real-life situations (from interprofessional education to multidisciplinary patient care teams). Skills learned from challenging situations are useful in developing long-term success strategies for teamwork.

This course is mostly application-based in nature, building on concepts previously taught in other courses (pathophysiology, medicinal chemistry, pharmacology, therapeutics). Based on our observation, students appear to perform better academically in application-based courses compared to those introducing new knowledge. We wonder if team performance would look differently in a less application-based course where new concepts are introduced. This is the only course in our curriculum that is delivered in a flipped/team-based learning approach. It takes time for students to become comfortable with this method, therefore thinking of ways to increase their overall satisfaction is of importance to us.

In order to prepare for peer-evaluations, CATME provides students with an opportunity to participate in a mock evaluation known as a Rater calibration activity. Based on our experience, we believe that the Rater calibration activity is essential for developing a level of comfort and understanding before moving on to real evaluations. We demonstrated this activity in class, and mandated that students complete it. Unfortunately, only half (51\%) of our students reported the Rater calibration activity was useful in understanding the setup of the peer evaluation form, and even fewer (45\%) in preparing them on how to evaluate their own team members. The majority of students $(86 \%)$ reported that team members evaluated them fairly. We question if this is the case, or if the students were just pleased with the peer-evaluation grade they received. CATME peer-evaluations allow multiple team members to receive the maximum grade of 5 . This is a non-budgeted approach, and we wonder if peerevaluations and Rater calibration activity would have been taken more seriously if a "budgeted" approach was used where a total score is divided between team members based on merit. ${ }^{12}$ Another software available on the market allows for customizable, budgeted peer evaluation that distributes a fixed number of points among participants. However, it lacks the ability to create student teams based on predetermined criteria. ${ }^{35}$ We hope that in the future that all these features will be integrated into one product.

There is a trend in our program of having students involved in teamwork in multiple courses, therefore our immediate areas of attention are student frustration in terms of personality suitability and team meeting times. An area for future consideration is to introduce students to various personality inventories earlier in the curriculum helping them with personal self-awareness and providing them with additional tools for team success. Placing students in the same teams as they take different courses during the same academic year might help to address time management concerns. To accomplish this task with a large class size, our faculty and the university registrar are exploring better ways to collaborate to enhance overall satisfaction for the next cohort of students.

This research has some limitations. It was performed in one school of pharmacy and the results cannot be extrapolated to other schools. Students received bonus points for completing the survey. Another possible limitation of this study is the difficulty of extrapolating the instructional method to other types of courses. The study was conducted in a single course in the curriculum, and this was the first time we utilized this strategy for team formation.

\section{CONCLUSION}

Based on our observations of teamwork in a large application-based course, students' performance correlates with their previous GPA. Academically stronger 


\section{American Journal of Pharmaceutical Education 2017; 81 (3) Article 47.}

students in mixed GPA teams appear to be at a slight disadvantage in terms of teamwork (tRAT) grade compared to similar students in higher GPA teams. There seems to be no difference in team performance for academically weaker students in lower GPA vs. mixed GPA teams. However, students in lower GPA teams are more satisfied with elements of teamwork. This makes teamwork in mixed GPA teams less preferable from both perspectives (performance and satisfaction).

When faculty are experimenting with new pedagogy and content delivery mechanisms in their courses, placing students in homogeneous teams can increase student teamwork satisfaction and possibly enhance overall course and learning satisfaction.

To help with our unanswered questions, future research may further focus on the effect of team academic ranking on students' individual performance, exploration of academically homogeneous versus heterogeneous teams in non-application based courses, and effects of budgeted versus non-budgeted peer-evaluations on students' contributions to teamwork.

\section{REFERENCES}

1. Ramsden P. Learning to Teach in Higher Education. New York, NY: RoutledgeFalmer; 2003.

2. Bonwell CC, Sutherland TE. The active learning continuum: choosing activities to engage students in the classroom. NDTL. 1996;1996(67):3-16.

3. Prince M. Does active learning work? A review of the research. $J$ Eng Educ. 2004;93(3):223-232.

4. Woolley AW, Chabris CF, Pentland A, Hashmi N, Malone TW. Evidence for a collective intelligence factor in the performance of human groups. Science. 2010;330(6004):686-688.

5. Slavin RE. Ability grouping and student achievement in elementary schools: a best-evidence synthesis. Rev Educ Res. 1987;57(3):293-336.

6. Cheng RW, Lam SF, Chan JC. When high achievers and low achievers work in the same group: the roles of group heterogeneity and processes in project-based learning. Br J Educ Psychol. 2008;78 (2):205-221.

7. Farland MZ, Sicat BL, Franks AS, Pater KS, Medina MS, Persky AM. Best practices for implementing team-based learning in pharmacy education. Am J Pharm Educ. 2013;77(8):Article 177. 8. Kaufman DB, Felder RM, Fuller H. Accounting for individual effort in cooperative learning teams. J Eng Educ. 2000;89(2):133-140. 9. Allen RE, Copeland J, Franks AS, et al. Team-based learning in US colleges and schools of pharmacy. Am J Pharm Educ. 2013;77(6): Article 115.

10. Romanelli F, Bird E, Ryan M. Learning styles: a review of theory, application, and best practices. Am J Pharm Educ. 2009;73 (1):Article 9.

11. Austin Z. Development and validation of the pharmacists' inventory of learning styles (PILS). Am J Pharm Educ. 2004;68(2). 12. Dow A, Lockeman K. Assessment in interprofessional education: defining behavioral targets. AACP Annual Meeting. 2015. 13. CATME Smarter teamwork. http://info.catme.org/. Accessed July 02, 2015.
14. Loughry ML, Ohland MW, Moore DD. Development of a theory-based assessment of team member effectiveness. Educ Psychol Meas. 2007;67(3):505-524.

15. Loughry ML, Ohland MW, Woehr DJ. Assessing teamwork skills for assurance of learning using CATME team tools. $J$ Marketing Educ. 2014;36(1):5-19.

16. Ohland MW, Loughry ML, Woehr DJ, et al. The comprehensive assessment of team member effectiveness: development of a behaviorally anchored rating scale for self- and peer evaluation. Academy of Management Learning \& Education. 2012;11(4):609-630. 17. Layton RA, Loughry ML, Ohland MW, Ricco GD. Design and validation of a web-based system for assigning members to teams using instructor-specified criteria. Adv Eng Educ. 2010;2(1):1-28. 18. Verleger M, Diefes-Dux H, Ohland MW, Besterfield-Sacre M, Brophy S. Challenges to informed peer review matching algorithms. J Eng Educ. 2010;99(4):397-408.

19. Crutchfield TN, Klamon K. Assessing the dimensions and outcomes of an effective teammate. J Educ Bus. 2014;89(6):285-291. 20. Ferreri SP, O'Connor SK. Redesign of a large lecture course into a small-group learning course. Am J Pharm Educ. 2013;77(1):Article 13. 21. Persky AM, Pollack GM. Transforming a large-class lecture course to a smaller-group interactive course. Am J Pharm Educ. 2010;74(9):Article 170.

22. Nicholl TA, Lou K. A model for small-group problem-based learning in a large class facilitated by one instructor. Am J Pharm Educ. 2012;76(6):Article 117.

23. Marshall LL, Nykamp DL, Momary KM. Impact of abbreviated lecture with interactive mini-cases vs traditional lecture on student performance in the large classroom. Am J Pharm Educ. 2014;78(10): Article 189.

24. Michaelsen LK, Parmelee D, McMahon KK, Levine RE. Teambased Learning for Health Professions Education: A Guide to Using Small Groups for Improving Learning. Sterling, VA: Stylus Publishing, LLC; 2008.

25. Ofstad W, Brunner LJ. Team-based learning in pharmacy education. Am J Pharm Educ. 2013;77(4):Article 70.

26. Hoegl M. Smaller teams - better teamwork: how to keep project teams small. Bus Horiz. 2005;48(3):209-214.

27. Drummond CK. Team-based learning to enhance critical thinking skills in entrepreneurship education. J Entrepren Educ. 2012;15:57-64.

28. Mott J, Peuker S. Achieving high functioning teams using team based learning in flipped classrooms. ASEE Annual Conference \& Exposition. 2015.

29. Peuker S, Mott J. Implementing team based learning in first-year engineering courses. FYEE conference. 2013.

30. Qualtrics: online survey software \& insight platform. http:// www.qualtrics.com/. Accessed April 08, 2015.

31. Hintze J. NCSS (number cruncher statistical system). 2007.

32. Chang A. StatsToDo - statistical programs. https://www.

statstodo.com/index.php. Accessed April 14, 2017.

33. Wielkiewicz RM, Prom CL, Loos S. Relationships of the leadership attitudes and beliefs scale with student types, study habits, life-long learning, and GPA. College Student J. 2005;39(1):31. 34. Goldwire M, Smith K, Haight R, et al. Impact of high and lowranking team-members on individual scores in a team-based-learning integrated literature evaluation (ILE) course. AACP Annual Meeting. 2015.

35. National University of Singapore. TEAMMATES. http:// teammatesv4.appspot.com/. Updated 2015. Accessed August 6, 2015 . 